in vivo $34: 2607-2612(2020)$

doi:10.21873/invivo.12078

\title{
Anatomical Versus Non-anatomical Resection for Hepatocellular Carcinoma, a Propensity-matched Analysis Between Taiwanese and Japanese Patients
}

\author{
SHIH-WEI HUANG ${ }^{1,2,3}$, PEI-YI CHU ${ }^{4,5,6}$, SHUNICHI ARIIZUMI $^{7}$, \\ CHARLES CHUNG-WEI LIN ${ }^{8,9}$, HON PHIN WONG ${ }^{1,2}$, DEV-AUR CHOU $^{1}$, \\ MING-TSUNG LEE ${ }^{10,11}$, HSING-JU WU ${ }^{10,12}$ and MASAKAZU YAMAMOTO ${ }^{7}$ \\ ${ }^{1}$ Division of General Surgery, Department of Surgery, Show Chwan Memorial Hospital, Changhua, Taiwan, R.O.C.; \\ ${ }^{2}$ IRCAD/AITS-Asian Institute of TeleSurgery, Show Chwan Health Care System, Changhua, Taiwan, R.O.C.; \\ ${ }^{3}$ Division of General Surgery, Department of Surgery, \\ Chang Bing Show Chwan Memorial Hospital, Changhua, Taiwan, R.O.C.; \\ ${ }^{4}$ School of Medicine, College of Medicine, Fu Jen Catholic University, New Taipei City, Taiwan, R.O.C.; \\ ${ }^{5}$ Department of Pathology, Show Chwan Memorial Hospital, Changhua, Taiwan, R.O.C.; \\ ${ }^{6}$ Department of Health Food, Chung Chou University of Science and Technology, Changhua, Taiwan, R.O.C.; \\ ${ }^{7}$ Department of Surgery, Institute of Gastroenterology, Tokyo Women's Medical University, Tokyo, Japan; \\ ${ }^{8}$ Show Chwan Memorial Hospital, Changhua, Taiwan, R.O.C.; \\ ${ }^{9}$ School of Medicine, National Yang-Ming University, Taipei, Taiwan, R.O.C.; \\ ${ }^{10}$ Research Assistant Center, Show Chwan Memorial Hospital, Changhua, Taiwan, R.O.C.; \\ ${ }^{11}$ Department of Nursing, Hungkuang University, Taichung, Taiwan, R.O.C.; \\ ${ }^{12}$ Department of Biology, National Changhua University of Education, Changhua, Taiwan, R.O.C.
}

\begin{abstract}
Background/Aim: The aim of the study was to compare the outcomes of anatomical resection (AR) versus non-anatomical resection (NAR) for Japanese and Taiwanese patients with single, resectable hepatocellular carcinoma (HCC). Patients and Methods: A propensity score matched (PSM) analysis was performed to compare the outcomes of the AR group to those of the NAR group. Tumor size $<5 \mathrm{~cm}$, T1 or T2 grade, without evidence of extrahepatic metastasis, invasion of portal or hepatic veins, or direct invasion of adjacent organs, were included in the study. Results: A total of 385 cases (Taiwanese 105, Japanese 280) were analyzed. After PSM, a total of 152 cases remain (Taiwan and Japan both 76 cases). Disease-free survival (DFS) and overall
\end{abstract}

This article is freely accessible online.

Correspondence to: Masakazu Yamamoto, MD, Department of Surgery, Institute of Gastroenterology, Tokyo Women's Medical University, 8-1, Kawada-cho, Shinjyuku-ku, Tokyo, Japan $162-$ 8666. Tel: +81 333575553, Fax: +81 333575553, email: yamamoto.masakazu@twmu.ac.jp

Key Words: Anatomical resection, non-anatomical resection, hepatocellular carcinoma, propensity score matched analysis, Taiwan, Japan, disease-free survival, overall survival. survival (OS) data were not significantly different between the two groups at 5 years follow-up. Conclusion: AR of HCC in Japanese patients has a similar 5-year DFS and OS as NAR of HCC in Taiwanese patients.

Hepatocellular carcinoma (HCC) is one of the leading causes of cancer-related death worldwide. Although more prevalent in Asia, incidence has been increasing in the western countries $(1,2)$. First-line treatment for HCC includes both liver resection and radio frequency ablation, although the former may have prognostic advantages over the latter, as shown in several recent studies, especially in those with solitary and small tumors (3). In recent years, prognosis of HCC has improved due to better surgical techniques, pre- and peri-operative management, and aggressive multimodal treatment strategies after tumor recurrence $(4,5)$. However, recurrence remains high after curative hepatectomy, and is believed to be the main cause of early death. Tumor recurrence usually occurs by dissemination of tumor cells in the portal vein or metachronous multi-centric hepatocarcinogenesis, and are considered the most important factors associated with poor prognosis (6-8). Regarding resection techniques, anatomic resection (AR) was first proposed in the 1980s, first with dye-staining technique (9), and later with the Glissonean pedical transection method (10). 
Both include pre-ischemic control of the portal pedicles, followed by systemic removal of one or more hepatic segments supplied by the tumor bearing portal tributaries. Proponents of AR theorizes that better outcomes can be achieved by this technique because it offers more effective removal of the intrahepatic metastases of HCC. Nonanatomic resection (NAR), on the other hand, leaves a greater portion of the parenchyma while focusing on achieving at least $1 \mathrm{~cm}$ tumor-free margin after surgery, preventing potential postoperative liver failure in patients with cirrhosis.

Studies comparing both techniques have shown mixed results, as some have demonstrated superiority of AR compared to NAR (11-14), while others have shown that NAR achieved similar long-term outcomes in terms of recurrencefree survival (RFS), and overall survival (OS) (15-18). However, most studies were non-randomized and retrospective in nature. The decision to undergo AR or NAR is often also dependent on the patient's liver reserve, and patients with better liver reserves are better candidates for AR, creating a potential selection, which may in turn lead to improved outcomes.

This can be avoided using propensity score-matched analysis. Three propensity-score matched analysis (19-21), however, did not show benefit in RFS and OS of AR compared to NAR. A recent randomized, controlled trial (RCT) was conducted in China (22), and showed an improved local recurrence (LR) rate at 2 year, but no difference for RFS or OS.

In the current study, we attempt to elucidate this issue by comparing data from two Institutions, one in Taiwan, and one in Japan, using propensity-score matched analysis, and evaluate the RFS and OS of patient with HCC undergoing resection.

\section{Patients and Methods}

Patients. Patients from two Institutions, one in Taiwan, Show Chwan Memorial Hospital (SCMH), and one in Japan, Tokyo Women's Memorial Hospital (TWMH), were retrospectively collected and analyzed. Between January 2007 and December 2014 in Japan, March 2012 and May 2018 in Taiwan, patients without evidence of extrahepatic metastasis, tumor invasion of portal or hepatic veins, or direct invasion of adjacent organs, with tumor size of $<5 \mathrm{~cm}$, were included in the study. Only patients for whom surgery was the first treatment modality were included. That is, patients who received portal vein embolization (PVE), trans-arterial chemoembolization (TACE), or radiofrequency ablation (RFA) were excluded. Surgical procedures were classified according to the Brisbane 2000 nomenclature of liver resection (23). AR is defined by complete removal of the $\geq 1$ Couinaud segment containing the tumor, after ischemic margin was confirmed by ligation of arterial and portal vein branch. NAR is defined as resection of the tumor with a margin of $\geq 1 \mathrm{~cm}$, whenever possible, without regarding the segmental anatomy of the liver. The technique chosen in both countries was determined by its respective surgeons, according to tumor size, location, and hepatic functional reserve. After initial selection, of the cases with T1
Table I. Basic information of patients before propensity score matching.

\begin{tabular}{|c|c|c|c|}
\hline & Japan $(\mathrm{N}=280)$ & Taiwan $(\mathrm{N}=105)$ & $p$-Value \\
\hline Gender & & & 0.762 \\
\hline Male & $220(78.6 \%)$ & $81(77.1 \%)$ & \\
\hline Female & $60(21.4 \%)$ & $24(22.9 \%)$ & \\
\hline Age $(\mathrm{M} \pm \mathrm{SD})$ & $68.0 \pm 9.5$ & $58.4 \pm 9.7$ & $<0.001$ \\
\hline $\mathrm{HBV}$ & & & $<0.001$ \\
\hline Positive & $66(23.6 \%)$ & $61(58.1 \%)$ & \\
\hline Negative & $214(76.4 \%)$ & $44(41.9 \%)$ & \\
\hline $\mathrm{HCV}$ & & & 0.050 \\
\hline Positive & $113(40.4 \%)$ & $31(29.5 \%)$ & \\
\hline Negative & $167(59.6 \%)$ & $74(70.5 \%)$ & \\
\hline Child Pugh & & & 0.015 \\
\hline $\mathrm{A}$ & $240(85.7 \%)$ & $95(90.5 \%)$ & \\
\hline B & $8(2.9 \%)$ & $4(3.8 \%)$ & \\
\hline $\mathrm{C}$ & $0(0.0 \%)$ & $2(1.9 \%)$ & \\
\hline N/A & $32(11.4 \%)$ & $4(3.8 \%)$ & \\
\hline $\mathrm{HCC}$ size $(\mathrm{M} \pm \mathrm{SD})$ & $4.5 \pm 3.0$ & $3.1 \pm 1.5$ & $<0.001$ \\
\hline HCC number & & & 0.826 \\
\hline Single & $232(82.9 \%)$ & $86(81.9 \%)$ & \\
\hline Multiple & $48(17.1 \%)$ & $19(18.1 \%)$ & \\
\hline $\mathrm{AFP}(\mathrm{M} \pm \mathrm{SD})$ & $2480.1 \pm 15369.6$ & $105.6 \pm 305.3$ & 0.011 \\
\hline $\mathrm{ICG}(\mathrm{M} \pm \mathrm{SD})$ & $13.7 \pm 8.9$ & $15.0 \pm 11.6$ & 0.453 \\
\hline Vessel invasion & & & 0.011 \\
\hline Positive & $54(13.9 \%)$ & $33(31.4 \%)$ & \\
\hline Negative & $226(80.7 \%)$ & $72(68.6 \%)$ & \\
\hline Type of surgery & & & $<0.001$ \\
\hline Laparoscopic & $13(4.6 \%)$ & $28(26.7 \%)$ & \\
\hline Open & $267(95.4 \%)$ & $77(73.3 \%)$ & \\
\hline
\end{tabular}

or T2 grade HCC, choosing only NAR from Taiwan and only AR from Japan. This study was approved by the institutional review board of Show Chwan Memorial Hospital, Taiwan and Tokyo Women's Medical University Hospital in Japan.

Pathological and histological examination. Pathological and histological examination were performed for the resected specimens, and the maximal diameter of the tumor determined the tumor size. Tumor differentiation and microscopic vascular invasion was determined.

Statistical analysis. Patient characteristics between two hospitals were analyzed by the Chi-square test, independent $t$-test, where appropriate. Data of the two hospitals were matched on age, sex, HBV, HCV, Child Pugh, and AFP using propensity score matching (PSM). The differences of disease free survival (DFS) and OS between the two hospitals were evaluated by Kaplan-Meier method with log-rank test. A $p$-value of $<0.05$ was considered statistically significant. IBM SPSS Statistics for Windows, version 24.0 (IBM Corp., Armonk, NY, USA) was used for the statistical analyses.

\section{Results}

After initial selection, of the total cases with $\mathrm{T} 1$ or $\mathrm{T} 2$ grade HCC, choosing only NAR from Taiwan and only AR from Japan, there were a total of 385 cases (Taiwanese 105 and 
Table II. Basic information of patients after propensity score matching.

\begin{tabular}{|c|c|c|c|}
\hline & Japan (N=76) & Taiwan $(\mathrm{N}=76)$ & $p$-Value \\
\hline Gender & & & 0.571 \\
\hline Male & $56(73.7 \%)$ & $59(77.6 \%)$ & \\
\hline Female & $20(26.3 \%)$ & $17(22.4 \%)$ & \\
\hline Age $(\mathrm{M} \pm \mathrm{SD})$ & $64.8 \pm 8.7$ & $62.3 \pm 9.0$ & 0.082 \\
\hline $\mathrm{HBV}$ & & & 0.415 \\
\hline Positive & $32(42.1 \%)$ & $37(48.7 \%)$ & \\
\hline Negative & $44(57.9 \%)$ & $39(51.3 \%)$ & \\
\hline $\mathrm{HCV}$ & & & 0.322 \\
\hline Positive & $34(44.7 \%)$ & $28(36.8 \%)$ & \\
\hline Negative & $42(55.3 \%)$ & $48(63.2 \%)$ & \\
\hline Child Pugh & & & 0.191 \\
\hline A & $69(90.8 \%)$ & $73(96.1 \%)$ & \\
\hline $\mathrm{B}$ & $7(9.2 \%)$ & $3(3.9 \%)$ & \\
\hline HCC size $(\mathrm{M} \pm \mathrm{SD})$ & $3.1 \pm 1.0$ & $3.1 \pm 1.5$ & 0.716 \\
\hline HCC number & & & 0.426 \\
\hline Single & $58(76.3 \%)$ & $62(81.6 \%)$ & \\
\hline Multiple & $18(23.7 \%)$ & $14(18.4 \%)$ & \\
\hline $\mathrm{AFP}(\mathrm{M} \pm \mathrm{SD})$ & $187.5 \pm 507.1$ & $103.9 \pm 203.8$ & 0.186 \\
\hline ICG $(\mathrm{M} \pm \mathrm{SD})$ & $14.4 \pm 8.8$ & $14.1 \pm 10.5$ & 0.916 \\
\hline Vessel invasion & & & 0.276 \\
\hline Positive & $18(23.7 \%)$ & $24(31.6 \%)$ & \\
\hline Negative & $58(76.3 \%)$ & $52(68.4 \%)$ & \\
\hline Type of surgery & & & $<0.001$ \\
\hline Laparoscopic & $2(2.6 \%)$ & $18(23.7 \%)$ & \\
\hline Open & $74(97.4 \%)$ & $58(76.3 \%)$ & \\
\hline
\end{tabular}

Japanese 280). Table I summarizes the peri-operative characteristics of both groups before PSM. There were significant differences in age, HBV and HCV status, Child Pugh scores, HCC size, and type of surgery performed (laparoscopy or open resection). No difference was noted in sex, HCC numbers, AFP, and ICG. After PSM using sex, age, HBV and HCV status, Child Pugh scores, HCC size, AFP levels, a total of 152 cases remain (Taiwan 76 cases, Japan 76 cases). Table II shows the results of PSM: no difference in peri-operative characteristics of the two groups, except the type of surgery (laparoscopic or open surgery).

The Kaplan-Meier analysis of the long-term outcomes showed that there is no significant difference in the two groups with regard to DFS, as well as OS (Figure 1).

\section{Discussion}

The choice of surgical technique to remove HCC has been an area of constant debate. Many factors may influence a surgeon's choice, including tumor location, tumor size, baseline liver functional reserve, and anatomical variations of portal pedicles. Postoperative liver failure is one of the most feared complications, thus the goal is to remove HCC with adequate margin while preserving maximal liver parenchyma. Compared to AR, NAR can spare more liver
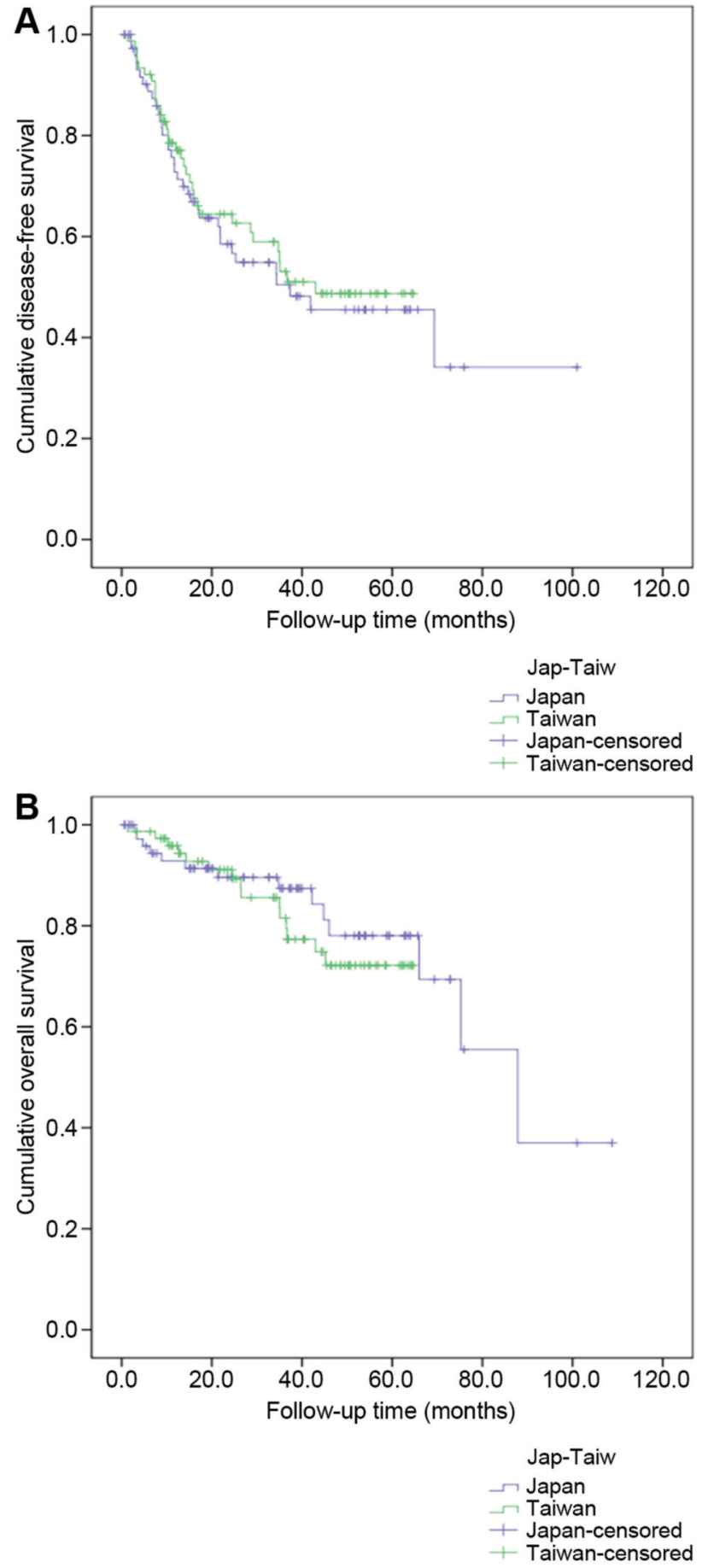

Figure 1. Kaplan-Meier curves of DFS (A) and OS (B) of the HCC patients with NAR from Taiwan and those with AR from Japan.

parenchyma after hepatectomy; therefore, it is often a preferred procedure for many surgeons. But what defines an adequate surgical margin? In one prospective, randomized trial, Shi et al. (24) compared patients with macroscopically 
solitary $\mathrm{HCC}$ of $\leq 2 \mathrm{~cm}$, and concluded that a resection margin of $2 \mathrm{~cm}$ had lower postoperative recurrence rate and improved survival outcomes. However, in most other studies, a wider margin was not protective against tumor recurrence. Poon et al. (25) retrospectively compared 150 patients with narrow margin $(\leq 1 \mathrm{~cm})$ to 138 patients with wide margin $(\geq 1$ $\mathrm{cm}$ ), and found similar recurrence rates. It was concluded that venous invasion or micro satellites was related to higher incidence of postoperative recurrence, which a wide resection margin could not prevent. In a recent systematic review by Tang et al. (26), which included four nonrandomized trials and the aforementioned randomized trial, it was also concluded that a resection margin $\geq 1 \mathrm{~cm}$ does not provide significant prognostic benefit compared to a resection margin of $<1 \mathrm{~cm}$.

In the present study, whilst comparing outcomes after hepatectomy from patients of two Institutions in two different countries, Japan and Taiwan, we showed the AR and NAR achieved similar outcomes in terms of RFS and OS. However, since we did not record recurrence patterns, no comparison was performed for local recurrence (LR) rates of the two groups.

Several retrospective studies have shown superiority of the AR method (11-14, 27-31). However, many of these studies were case series, and had significant bias in patient selection. Those in the AR group usually had better baseline liver functional reserve, which may skew the recurrence and survival data. Some studies attempted to reduce patient selection bias by performing propensity-match analysis. In the nationwide survey in Japan, consisting of 5,781 patients with solitary HCC, AR resulted in better DFS and OS than NAR. However, after patients were stratified according to tumor size $(<2 \mathrm{~cm}, 2-5 \mathrm{~cm}$, or $>5 \mathrm{~cm})$, only patients with tumor size of $2-5 \mathrm{~cm}$ and those who underwent AR demonstrated improved DFS and OS (14). Another large, retrospective study compared 710 patients with primary, solitary HCC of $<5.0 \mathrm{~cm}$ in diameter by either AR or NAR in Japan and Korea. In that study, AR decreased the risk of tumor recurrence and improved OS after using propensity score matched analysis (31). Multiple intrahepatic recurrences also occurred significantly less frequently in the AR group as well as recurrence within 2 years after hepatectomy. Using univariate analysis, several oncologic characteristics were also analyzed, and noted that larger tumor $(\geq 2.9 \mathrm{~cm})$, poorly differentiated tumor, and tumors with microscopic vascular invasion were associated with improved survival after AR.

Several studies suggested that AR confers no added benefit compared to NAR. Tomimamu et al. (18) showed that in patients with small $\mathrm{HCC}(\leq 3.0 \mathrm{~cm})$ and well-functioning livers, NAR or AR resulted in similar recurrence and survival rates. Marubashi et al. (21) showed similar results in a larger patient cohort, which included patients with solitary or multiple tumors with no macroscopic vascular invasion. Both studies were single-center, propensity score matched analysis. However, microvascular invasion rates were different among the two resection techniques, and can be a confounding factor that influence the outcomes.

Other factors important to patient survival, including tumor pathology, pre-operative assessment of liver functions, classifications of liver staging, standardization of surgical techniques, including the use of hanging maneuvers and laparoscopy, intra- and preoperative complications, blood loss, intra-operative transfusions, are not equally discussed or recorded in the above-mentioned studies. These are potential confounders that can lead to significant heterogeneity among studies, rendering the general applicability difficult. Other factors include patient characteristics, which in both countries are very different before PSM. Although PSM may be able to offset these differences, there may still be other hidden factors that will influence the analysis results.

Another issue is related to anatomical variations in the liver. In Couinaud segments 7 and 8,33-70\% are supplied by $\geq 2$ tertiary branches arising from the same or different secondary branches $(32,33)$. For these tumors, proper AR requires identification of all feeding branches. This step is technically challenging, since a larger volume of parenchyma of the non-involved segment needs to be dissected to determine the involved Glissonean pedicle. The difficulty may render heterogeneity in surgical techniques among different surgeons.

Feng et al. (22) conducted the only double-blind, prospective, randomized trial to date. 53 patients (AR group), and 52 patients (NAR group) with median tumor size of $5.0 \mathrm{~cm}$ were randomized and underwent AR and NAR. More patients achieved surgical margin of $\geq 20 \mathrm{~mm}$ in the AR group ( $52 \%$ vs. $30 \%, p=0.023)$. Incidence of local recurrence (LR) at 2 years was $30 \%$ and $59 \%$ in the AR and NAR groups, respectively. Median time to first LR was longer in the AR group, compared to NAR (53 vs. 10 months, $p=0.01)$. However, no difference was observed in RFS and OS.

Laparoscopic versus open resection is one factor that differed significantly between the two cohorts in this study. In the Taiwan Institute, higher percentage of patients received laparoscopic surgery, while in the Japanese institute, open surgery is preferred. This may be due to institutional preference and available expertise. The choice of technique may also be influenced by patient characteristics, such that NAR is more suitable for patients with $\mathrm{HBV}$, small size and low AFP. In terms of outcomes, studies comparing the two approaches have shown that, compared to open surgery, laparoscopic hepatectomy can achieve similar short-term oncologic outcomes (34-36), while achieving better postoperative recovery. In a propensity-matched analysis, Cheung et al. (37) concluded that the laparoscopic group had 
less blood loss, shorter operation time, and shorter hospital stay. With a follow-up of more than 5 years, it was even concluded that the laparoscopic approach offers favorable OS and DFS compared to open hepatectomy. Although the survival benefit of laparoscopic surgery is controversial, the reduced morbidity of open hepatectomy warrant wider applications in Japanese institutions. One hypothesis could be that the benefit of AR in the Japanese cohort is offset by the lack of laparoscopy. Perhaps under a more aggressive approach, by performing laparoscopic surgery in the Japanese group could achieve better survival outcomes. Similarly, in the Taiwanese cohort, by performing more AR, while maintaining the same rate of laparoscopic surgery, better outcomes could also be achieved.

In conclusion, in the current study, we demonstrated that, for patients with $\mathrm{T} 1$ or T2 HCC, AR and NAR achieved similar RFS and OS, in the hands of surgeons in two different countries. Further randomized controlled studies are needed to evaluate the benefit of these techniques in patients with HCC in different stages and liver function reserve.

\section{Conflicts of Interest}

The Authors have no conflicts of interest to declare.

\section{Authors' Contributions}

SWH collected and analyzed the clinical data, and drafted the manuscript. PYC performed pathological and histological examination. SA, CCWL, HPW and DAC collected and analyzed the clinical data. MTL analyzed the clinical data and performed statistical analysis. HJW edited and revised the final draft of manuscript. MY designed and coordinated the study.

\section{Acknowledgements}

The Authors would like to thank Fang-Yu Shang from Show Chwan Memorial Hospital for her assistance in collecting clinical data.

\section{References}

1 Bosch FX, Ribes J, Diaz M and Cleries R: Primary liver cancer: worldwide incidence and trends. Gastroenterology 127(5 Suppl 1): S5-S16, 2004. PMID: 15508102. DOI: 10.1053/j.gastro. 2004.09.011

2 Feng Q, Chi Y, Liu Y, Zhang L and Liu Q: Efficacy and safety of percutaneous radiofrequency ablation versus surgical resection for small hepatocellular carcinoma: a meta-analysis of 23 studies. J Cancer Res Clin Oncol 141(1): 1-9, 2015. PMID: 24889505. DOI: 10.1007/s00432-014-1708-1

3 Hasegawa K, Aoki T, Ishizawa T, Kaneko J, Sakamoto Y, Sugawara Y and Kokudo N: Comparison of the therapeutic outcomes between surgical resection and percutaneous ablation for small hepatocellular carcinoma. Ann Surg Oncol 21 Suppl 3: S348-355, 2014. PMID: 24566865. DOI: 10.1245/s10434-0143585-x
4 Kim DY and Han KH: How to improve treatment outcomes for hepatocellular carcinoma of intermediate and advanced stage. Dig Dis 30(6): 598-602, 2012. PMID: 23258101. DOI: 10.1159/000343088

5 Colombo M, Raoul JL, Lencioni R, Galle PR, Zucman-Rossi J, Banares R, Seehofer D, Neuhaus $\mathrm{P}$ and Johnson $\mathrm{P}$ : Multidisciplinary strategies to improve treatment outcomes in hepatocellular carcinoma: a European perspective. Eur J Gastroenterol Hepatol 25(6): 639-651, 2013. PMID: 23628963. DOI: $10.1097 /$ MEG.0b013e32835e33bb

6 Nakashima $\mathrm{T}$ and Kojiro M: Pathologic characteristics of hepatocellular carcinoma. Semin Liver Dis 6(3): 259-266, 1986. PMID: 3022387. DOI: 10.1055/s-2008-1040608

7 Park JH, Koh KC, Choi MS, Lee JH, Yoo BC, Paik SW, Rhee JC and Joh JW: Analysis of risk factors associated with early multinodular recurrences after hepatic resection for hepatocellular carcinoma. Am J Surg 192(1): 29-33, 2006. PMID: 16769271. DOI: 10.1016/j.amjsurg.2005.11.010

8 Kamiyama T, Nakanishi K, Yokoo H, Kamachi H, Tahara M, Kakisaka T, Tsuruga Y, Todo S and Taketomi A: Analysis of the risk factors for early death due to disease recurrence or progression within 1 year after hepatectomy in patients with hepatocellular carcinoma. World J Surg Oncol 10: 107, 2012. PMID: 22697061. DOI: 10.1186/1477-7819-10-107

9 Makuuchi M, Hasegawa $\mathrm{H}$ and Yamazaki S: Ultrasonically guided subsegmentectomy. Surg Gynecol Obstet 161(4): 346350, 1985. PMID: 2996162.

10 Takasaki K: Glissonean pedicle transection method for hepatic resection: a new concept of liver segmentation. J Hepatobiliary Pancreat Surg 5(3): 286-291, 1998. PMID: 9880776. DOI: $10.1007 / \mathrm{s} 005340050047$

11 Imamura H, Matsuyama Y, Miyagawa Y, Ishida K, Shimada R, Miyagawa S, Makuuchi $M$ and Kawasaki S: Prognostic significance of anatomical resection and des-gamma-carboxy prothrombin in patients with hepatocellular carcinoma. Br J Surg 86(8): 1032-1038, 1999. PMID: 10460639. DOI: 10.1046/ j.1365-2168.1999.01185.x

12 Yamamoto M, Takasaki K, Ohtsubo T, Katsuragawa H, Fukuda $\mathrm{C}$ and Katagiri S: Effectiveness of systematized hepatectomy with Glisson's pedicle transection at the hepatic hilus for small nodular hepatocellular carcinoma: retrospective analysis. Surgery 130(3): 443-448, 2001. PMID: 11562668. DOI: 10.1067/ msy.2001.116406

13. Wakai T, Shirai Y, Sakata J, Kaneko K, Cruz PV, Akazawa K and Hatakeyama K: Anatomic resection independently improves long-term survival in patients with T1-T2 hepatocellular carcinoma. Ann Surg Oncol 14(4): 1356-1365, 2007. PMID: 17252289. DOI: $10.1245 / \mathrm{s} 10434-006-9318-\mathrm{Z}$

14 Eguchi S, Kanematsu T, Arii S, Okazaki M, Okita K, Omata M, Ikai I, Kudo M, Kojiro M, Makuuchi M, Monden M, Matsuyama Y, Nakanuma Y, Takayasu K and Liver Cancer Study Group of Japan: Comparison of the outcomes between an anatomical subsegmentectomy and a non-anatomical minor hepatectomy for single hepatocellular carcinomas based on a Japanese nationwide survey. Surgery 143(4): 469-475, 2008. PMID: 18374043. DOI: 10.1016/j.surg.2007.12.003

15 Kaibori M, Matsui Y, Hijikawa T, Uchida Y, Kwon AH and Kamiyama Y: Comparison of limited and anatomic hepatic resection for hepatocellular carcinoma with hepatitis C. Surgery 139(3): 385394, 2006. PMID: 16546504. DOI: 10.1016/j.surg.2005.08.035 
16 Tanaka K, Shimada H, Matsumoto C, Matsuo K, Nagano Y, Endo I and Togo S: Anatomic versus limited nonanatomic resection for solitary hepatocellular carcinoma. Surgery 143(5): 607-615, 2008. PMID: 18436008. DOI: 10.1016/j.surg.2008.01.006

17 Kang CM, Choi GH, Kim DH, Choi SB, Kim KS, Choi JS and Lee WJ: Revisiting the role of nonanatomic resection of small $(<$ or $=4 \mathrm{~cm})$ and single hepatocellular carcinoma in patients with well-preserved liver function. J Surg Res 160(1): 81-89, 2010. PMID: 19577249. DOI: 10.1016/j.jss.2009.01.021

18 Tomimaru Y, Eguchi H, Marubashi S, Wada H, Kobayashi S, Tanemura M, Umeshita K, Doki Y, Mori M and Nagano H: Equivalent outcomes after anatomical and non-anatomical resection of small hepatocellular carcinoma in patients with preserved liver function. Dig Dis Sci 57(7): 1942-1948, 2012. PMID: 22407377. DOI: 10.1007/s10620-012-2114-7

19 Ishii M, Mizuguchi T, Kawamoto M, Meguro M, Ota S, Nishidate T, Okit, K, Kimura Y, Hui TT and Hirata K: Propensity score analysis demonstrated the prognostic advantage of anatomical liver resection in hepatocellular carcinoma. World J Gastroenterol 20(12): 3335-3342, 2014. PMID: 24696614. DOI: $10.3748 /$ wjg.v20.i12.3335

20 Okamura Y, Ito T, Sugiura T, Mori K and Uesaka K: Anatomic versus nonanatomic hepatectomy for a solitary hepatocellular carcinoma: a case-controlled study with propensity score matching. J Gastrointest Surg 18(11): 1994-2002, 2014. PMID: 25213582. DOI: 10.1007/s11605-014-2646-6

21 Marubashi S, Gotoh K, Akita H, Takahashi H, Ito Y, Yano M, Ishikawa $\mathrm{O}$ and Sakon $\mathrm{M}$ : Anatomical versus non-anatomical resection for hepatocellular carcinoma. Br J Surg 102(7): 776784, 2015. PMID: 25847111. DOI: 10.1002/bjs.9815

22 Feng X, Su Y, Zheng S, Xia F, Ma K, Yan J, Li X, Tang W, Wang S, Bie P and Dong J: A double blinded prospective randomized trial comparing the effect of anatomic versus nonanatomic resection on hepatocellular carcinoma recurrence. HPB (Oxford) 19(8): 667-674, 2017. PMID: 28499749. DOI: 10.1016/j.hpb.2017.04.010

23 Strasberg SM: Nomenclature of hepatic anatomy and resections: a review of the Brisbane 2000 system. J Hepatobiliary Pancreat Surg 12(5): 351-355, 2005. PMID: 16258801. DOI: 10.1007/ s00534-005-0999-7

24 Shi M, Guo RP, Lin XJ, Zhang YQ, Chen MS, Zhang CQ, Lau WY and Li JQ: Partial hepatectomy with wide versus narrow resection margin for solitary hepatocellular carcinoma: a prospective randomized trial. Ann Surg 245(1): 36-43, 2007. PMID: 17197963. DOI: 10.1097/01.sla.0000231758.07868.71

25 Poon RT, Fan ST, Ng IO and Wong J: Significance of resection margin in hepatectomy for hepatocellular carcinoma: A critical reappraisal. Ann Surg 231(4): 544-551, 2000. PMID: 10749616. DOI: 10.1097/00000658-200004000-00014

26 Tang $\mathrm{YH}$, Wen TF and Chen X: Resection margin in hepatectomy for hepatocellular carcinoma: a systematic review. Hepatogastroenterology 59(117): 1393-1397, 2012. PMID: 22683956. DOI: $10.5754 /$ hge 10600

27 Regimbeau JM, Kianmanesh R, Farges O, Dondero F, Sauvanet A and Belghiti J: Extent of liver resection influences the outcome in patients with cirrhosis and small hepatocellular carcinoma. Surgery 131(3): 311-317, 2002. PMID: 11894036. DOI: $10.1067 / \mathrm{msy} .2002 .121892$

28 Hasegawa K, Kokudo N, Imamura H, Matsuyama Y, Aoki T, Minagawa M, Sano K, Sugawara Y, Takayama T and Makuuchi
M: Prognostic impact of anatomic resection for hepatocellular carcinoma. Ann Surg 242(2): 252-259, 2005. PMID: 16041216. DOI: 10.1097/01.sla.0000171307.37401.db

29 Cho YB, Lee KU, Lee HW, Cho EH, Yang SH, Cho JY, Yi NJ and Suh KS: Anatomic versus non-anatomic resection for small single hepatocellular carcinomas. Hepatogastroenterology 54(78): 1766-1769, 2007. PMID: 18019714.

30 Yamashita Y, Taketomi A, Itoh S, Kitagawa D, Kayashima H, Harimoto N, Tsujita E, Kuroda Y and Maehara Y: Longterm favorable results of limited hepatic resections for patients with hepatocellular carcinoma: 20 years of experience. J Am Coll Surg 205(1): 19-26, 2007. PMID: 17617328. DOI: 10.1016/ j.jamcollsurg.2007.01.069

31 Kaibori M, Kon M, Kitawaki T, Kawaura T, Hasegawa K, Kokudo N, Ariizumi S, Beppu T, Ishizu H, Kubo S, Kamiyama T, Takamura H, Kobayashi T, Kim DS, Wang HJ, Kim JM, Han DH, Park SJ, Kang KJ, Hwang S, Roh Y, You YK, Joh JW and Yamamoto M: Comparison of anatomic and non-anatomic hepatic resection for hepatocellular carcinoma. J Hepatobiliary Pancreat Sci 24(11): 616626, 2017. PMID: 28887834. DOI: $10.1002 /$ jhbp.502

32 Cho A, Okazumi S, Takayama W, Takeda A, Iwasaki K, Sasagawa S, Natsume T, Kono T, Kondo S, Ochiai T and Ryu M: Anatomy of the right anterosuperior area (segment 8) of the liver: evaluation with helical CT during arterial portography. Radiology 214(2): 491-495, 2000. PMID: 10671598. DOI: 10.1148/radiology.214.2.r00fe38491

33 Kogure K, Kuwano H, Fujimaki N, Ishikawa H and Takada K: Reproposal for Hjortsjo's segmental anatomy on the anterior segment in human liver. Arch Surg 137(10): 1118-1124, 2002. PMID: 12361415. DOI: 10.1001/archsurg.137.10.1118

34 Yoon YI, Kim KH, Kang SH, Kim WJ, Shin MH, Lee SK, Jung DH, Park GC, Ahn CS, Moon DB, Ha TY, Song GW, Hwang S and Lee SG: Pure laparoscopic versus open right hepatectomy for hepatocellular carcinoma in patients with cirrhosis: A Propensity Score Matched Analysis. Ann Surg 265(5): 856-863, 2017. PMID: 27849661 . DOI: $10.1097 /$ SLA.0000000000002072

$35 \mathrm{Xu} \mathrm{HW}$, Liu F, Li HY, Wei YG and Li B: Outcomes following laparoscopic versus open major hepatectomy for hepatocellular carcinoma in patients with cirrhosis: a propensity score-matched analysis. Surg Endosc 32(2): 712-719, 2018. PMID: 28726140. DOI: $10.1007 / \mathrm{s} 00464-017-5727-2$

36 Untereiner X, Cagniet A, Memeo R, Cherkaoui Z, Piardi T, Severac F, Mutter D, Kianmanesh R, Wakabayashi $T$, Sommacale D and Pessaux P: Laparoscopic hepatectomy versus open hepatectomy for the management of hepatocellular carcinoma: a comparative study using a propensity score matching. World J Surg 43(2): 615-625, 2019. PMID: 30341471. DOI: $10.1007 / \mathrm{s} 00268-018-4827-\mathrm{z}$

37 Cheung TT, Dai WC, Tsang SH, Chan AC, Chok KS, Chan SC and Lo CM: Pure Laparoscopic hepatectomy versus open hepatectomy for hepatocellular carcinoma in 110 patients with liver cirrhosis: a propensity analysis at a single center. Ann Surg 264(4): 612-620, 2016. PMID: 27433917. DOI: 10.1097/SLA. 0000000000001848

Received May 15, 2020

Revised June 18, 2020

Accepted June 29, 2020 